$D$-region (below $90 \mathrm{~km}$ ), and the lower portion of the $E$ region up to about $100 \mathrm{~km}$, since it is at these heights that the absorption of radio waves of all frequencies mainly occurs, and that the phase and polarization of the lower frequencies is determined. For this exploration of the lower atmosphere, a quasi-stationary pattern is set up by a vertical beam of waves at $200 \mathrm{kc} / \mathrm{s}$, which are reflected back from the ionosphere. A rocket fired up through this pattern measures the characteristics-strength and polarization - of the field, and these depend on the height distribution of the electrons and on the frequency with which they collide with neutral molecules. The field pattern, as recorded on three mutually perpendicular aerials carried in the rocket, is complicated, and attempts are being made to explain the results on the basis of a 'model ionosphere' suggested by theoretical workers in the subject.

The staff of the Radio Research Station have taken full advantage of the opportunity provided by the Canadian 'Top-side Sounder' project to explore the characteristics of the ionosphere from above the height of maximum ionization. The satellite travelling at a height of about $1,000 \mathrm{~km}$ carries a complete ionosphere sounding station, and telemetry records have been obtained when the satellite passes over the Station at Slough and the outstations at the Falkland Islands and Singapore. Some typical results are illustrated in the report, and these, together with others obtained by their Canadian and United States colleagues, have been discussed previously in Nature $(197,636 ; 1963)$.

For the past two years, oblique incidence sounding of the ionosphere has been carried out over a long-distance path between New Delhi and Slough. As the frequency is raised, the value at which the signal becomes weak or fades out is termed the maximum usable frequency. In this way, the highest useful frequency for a practical communication circuit over this path can be found at any time, and used to adjust the long-term average values which are provided from the prediction charts issued by the
Station. Trials have been conducted over a number of paths in co-operation with the various civil and military authorities operating the related circuits. The technique should be found of advantage during the coming period of minimum sunspot activity when the usable frequencies will be severely compressed into a narrow part of the spectrum, and when any information which enables the operator to work outside it will be of great value.

To provide the facilities for the expansion of the research programme on the lines described here, some curtailment has been necessary on a few of the items which have received much attention in the past. The short-term ionospheric forecasting has been reduced to the provision of an ionospheric index for use with the long-term world charts which are now available for each of the $24 \mathrm{~h}$. The information in these charts is based on the knowledge and experience obtained at the Radio Research Station in studying the characteristics of the ionosphere over more than two sunspot periods. The main programme of radio noise measurements, which was in progress for some ten years before the International Geophysical Year of 1957-58 and has continued since, has now been terminated. Finally, the preparation for publication of the Abstracts and References to radio literature, which has been the responsibility of the radio staff of the Department of Scientific and Industrial Research since 1926, was discontinued at the end of 1962 , in the knowledge that the field surveyed was becoming increasingly covered by other abstracting services. Acknow. ledgment from users of the Abstracts and References is paid to the small section of the staff who, over the period of thirty-six years, devoted themselves to this work with unusual enthusiasm and energy.

Other features of the director's report show that he and his staff are maintaining and improving the high traditions of the Radio Research Station in advancing knowledge in the field of radio science in step with the contemporary progress being accomplished by the launching of satellites for space research. R. L. SMITH-Rose

\title{
TELEMETRY APPLIED TO ENGINEERING AND MEDICINE
}

\begin{abstract}
AEETING was held at the Institution of Electrical Engineers on August 8 in connexion with the first International Telemetering Conference, which will be held at the Institution during September 23-27.

The chairman of the U.K. Organizing Committee, Dr. J. S. McPetrie, outlined the rapid growth of telemetry, the science/technology of measurement at a distance. He explained that the term telemetry applied to all cases in which the information from any form of measurement was transferred to some point other than that at which the measurement itself was made. This means that the measurement has to be made by a special type of equip. ment, known as a transducer, which transforms the result of the measurement into a form, usually electrical, suitable for transmission to the remote receiving point where the reading is required. Telemetry assumed great importance towards the end of the Second World War with the emergence of guided weapons and later satellites and space vehicles. In the development of such complex equipment, in which reliability of performance is of paramount importance, it is essential to know at all times how the various component parts are operating, and for this purpose some form of telemetry is essential. Telemetry, of course, is not limited to the fields of weapons and satellites but has many civil applications in which British scientists have played a leading part. All these fields will be covered by papers to be presented at the Conference.
\end{abstract}

The chairman then introduced Mr. Pruss, a member of the North American Organizing Committee. Mr. Pruss gave a brief account of the various conferences on telemetry which have been held annually in the United States since 1951. The committee responsible for these conferences, realizing that much work on the subject had been carried out in countries other than the United States, considered that the time had arrived when a conference of a more international character would be extremely useful. It was suggested, therefore, that such a conference should be held in Europe, preferably London. The Institution of Electrical Engineers and the British Institution of Radio Engineers agreed jointly to sponsor this conference. The international character of the forthcoming conference is indicated by the fact that the 500 600 delegates expected will come from some seventeen different countries, including the U.S.S.R., Poland, Australia, Japan and South Africa, while 59 papers will be presented by authors from the United States, the United Kingdom, Canada, Belgium, France, Australia and Japan.

Dr. R. H. Barker, who is chairman of the Programme Committee, next gave a brief summary of the scope of the papers to be presented at the Conference. It opens with an introductory session, at which three papers will be discussed. Two of these deal in a general way with the present state of the art of telemetry, while the third paper outlines the history of the extensive use of telemetry 
in the United Kingdom by the electricity supply authorities.

In the second session, on "Industrial Systemas", oight papers deal with such topics as the part telemetry has played in the control of a 2,300-mile pipeline for natural gas as well as in an investigation of the vibration of blades in a large turbine. The third session is on "Transducers" of different types, whilo the fourth session is devoted to "Geophysies and Biomedicine". This latter session should be of particular interest to the Iayman, as one of the papers describes experiments made using minute radio transmitters, so-called radio pills, in the human body for the diagnosis of disease. Prof. Stewart Mackay (United States), the author of this paper, was present at the meeting and gave an interesting summary of his research work.

The next three sessions, on "Recording", "Data Processing" and "Error Detection", are for the specialist, and with more than twenty papers on these subjects lively discussions are to be expected. The last session, tho eighth, is on "Aerospaco Systems". As this is a subject of the greatest topical interest, a whole day has been allowed for presentation and discussion.

One of the main functions of such a conference is to bring together for discussion and interchange of information in the laboratory workers in the particular field under roviow. For this reason, a number of visits of a techrical nature have been arranged, and reference to them was made by Mr. J. Langham Thompson, who is chairman of the Visits Committoo. Telemetry, ho said, plays an important part in the remote control of olectric power stations. Delegates will be able to see this on a visit to the main grid control centre of the Central Electricity Generating Board at Redbourn, near St. Albans. They will also be able to visit the Research Laboratories of the Central Flectricity Generating Board, Leatherhead. For those interested in the medical aspects of telemetry, visits have been arranged to the National Institute of Medical Re- search at Mill Hill and the Medical Research Council Bioengineering Laboratories at Hampstcad. Oceanographers will bo ablo to seo the work at the National Institute of Oceanography, Godalming, Surrey. Telemetry techniques are of great importance in coal mining and train signalling, so visits have also been arranged to the Mining Research Establishment, Isleworth, and the British Railways Track Control Centre, Hackney Downs. The various methods for tracking satellites and the procedures used for analysing the complex data from world-wide observations of orbiting satollites will be seen on a visit to the Radio Research Station, Datchet.

Immediately bofore the moeting, a cable was received from the United States offering to make available from the Pacific Missile Range in California a 'Constellation' aircraft fully instrumented as a flying laboratory and including tolemetry equipment. Dr. MePetrie exprossed the hope that the aircraft could bo accommodated at the Royal Aircraft Establishment, Bedford. where a visit has already been arranged for those delogatos interested in the flight testing of aircraft, one of the most important fields in the application of telemetry.

In answer to a question, Dr. MePetrie explained that the papers presented at each session would not be read by their individual authors but summarized as at group by a rapporteur who would be a specialist in the subject. With this procedure, it was hoped that more time would be available for discussion in which each author would have an opportunity to participate.

During the period of the Conference, an exhibition of telemetry equipment will be held at the Hilton Hotel. A shuttle coach service will be run between the Conference at the Institution of Electrical Engineers and the Hilton Hotel for the convenience of the delegates. A smaller exhibition illustrating particular points in the papers presented at the Conference will be arranged at the Institution.

J. S. McPetrie

\section{THE MUSEUMS ASSOCIATION}

T HE sixty-ninth annual conference of the Museums Association was held at Newcastle upon 'Tyne during July 22-26 by invitation of the City and King's College and under the presidency of Sir Trenchard Cox, director of the Victoria and Albert Museum, London.

The conforonce opened with a welcome from the Lord Mayor and the Rector of King's College, followed by the presidential address. In this, Sir Trenchard naturally roferred to the outstanding Survey of Provincial Museums and Galleries*, recently issued by the Standing Commission on Museums and Galleries. He elso stressed the importance of a definite policy for purchases and referred to the several building projects which are now engaging the activities of architects and directors.

The Rt. Hon. Sir Edward Boyle, Minister of Education, also addressed the delegates and especially reforrod to the importance of the various museum services for schools which now form such a prominent part of the museum movement in Britain. On many oceasions he had wit. nessed the appreciation of the toaching profession for the services rendered. Referring to the Survey, he hoped that it would be implemented when Britain's economic position made this possible. Ho felt that teacher training colleges should include courses on the use that the profession could make of their local museums.

The main part of the conference naturally directed attention on the Survey, and delegates were favoured with the presence of the Earl of Rosse, chairman of the Standing

* Standing Commission on Museums and Galleries. Survey of Provincia Museums and Galleries. Pp. 302. (Condon: H.M.S.0., 1063.) 30 s.
Commission. The Hon. Nicholas Ridley and Mr. Kenneth Robinson also spoke and gave support for the main recommendations of the Survey, though tho former was in favour of admission charges to museums. An informal vote emphatically rejected this suggestion. Mr. Robinson felt that poor museums discredited the movement and hoped that the Standing Commission would have made definite proposals on this subject.

In general, it can definitely be stated that the Conference was in genoral agreemont with the recommendations of the Standing Commission, especially as regards the emphasis it placed on the future part to be played by the Area Museum Councils.

Members welcomed the information, given by the Countess of Albemarle, that the Carnogio Trusteos hoped to continue their support for museums during the next quinquennium (1965-70).

At the annual general meeting, the conference agreed to new regulations regarding tho award of the Diploma of the Museums Association whereby graduates will bo exempted from the intermediate examination. The final examination will be taken by all candidates and include a thesis and a practical examination. It is hoped that revised regulations for the Technical Certificate will bo roady for next year's conference, for which Dr. D. Dilwyn John, director of the National Museum of Wales, was elected president.

Social functions included receptions by the Lord Mayor and the Rector of King's College, visits to local museums and tours to the Roman Wall and Farne Islands. F. S. WALLIS 